\title{
Alprostadil plus Vacuum (VITARUM) in severe erectile dysfunction (ED)
}

\author{
Franco Mantovani \\ Clinica San Giovanni, Milan, Italy.
}

\begin{abstract}
Summary Objectives: Severe erectile dysfunction
(ED) is not uncommon, as can be seen from the epidemiological literature, and there are several possible causes, which are not always known, or leastways evident. Having ascertained the ineffectiveness, intolerance to or rejection of pharmacological aids, the option of prosthetic surgery remains, but before this, it may be wise when feasible to use Alprostadil cream in association with Vacuum device.

Material and methods: 12 patients, aged between 55 and 65 years, with severe erectile dysfunction without palpable cavernous fibrosis, were instructed to self-insert into the urethral meatus, $3 \mathrm{mg}$ of Alprostadil cream, sufficient to make it easy to place the Vacuum device over the penis. Results: In the cases observed, the preliminary use of Alprostadil cream fast produced an erection with enough rigidity to place the Vacuum. A sufficient erection was maintained, obviously using an elastic ring at the base of the penis, to achieve penetration. The reproducibility of the use of Alprostadil cream with Vacuum device was then confirmed at home, to the satisfaction of the patients.
\end{abstract}

KEY WORDS: Erectile dysfunction; Alprostadil cream; Vacuum device.

Submitted 14 April 2017; Accepted 23 April 2017

\section{INTRODUCTION}

Severe erectile dysfunction (ED) is such a relentless health care problem that often causes an agonising ordeal to the patient and constitutes a challenge for the dedicated specialist who has to deal with it in daily practice. It is well-known that this condition is anything but rare, as is documented in the epidemiological literature, and that there are several causes, although not always well known or even clarifiable (1).

In addition to adverse outcomes of radical pelvic surgery, these include excessive smoking, vasculopathies due to uncompensated diabetes, and even undiagnosed psychoses. Having ascertained the ineffectiveness, intolerance or rejection of pharmacological treatments, prosthetic surgery remains an option, but it may be wise and certainly feasible, to try the use of Alprostadil cream in association with Vacuum device (VITARUM) first.

\begin{abstract}
Materials AND Methods
Twelve patients aged between 55 and 65 years, with severe erectile dysfunction scored between 15 and 20 by the International Index of Erectile Function (IIEF-15) index and an aetiology falling under the categories mentioned above (but excluding palpable cavernosal fibrosis that was a criterium of exclusion for this treatment) (2), were instructed to self-insert into their own urethral meatus, $3 \mathrm{mg}$ of Alprostadil, conveyed in a micro solution gel with dodecyl dimethylammonium propionate (Vitaros).

This patented natural surfactant technology allows for a rapid absorption of the drug, resulting in a penile turgidity, which is initially modest, but adequate to easily place the Vacuum device onto the penis avoiding repeated attempts. The Vacuum device is a tool of the andrological therapeutic armamentarium for many years.
\end{abstract}

\section{Results}

In the cases observed, the preliminary turgidity obtained with Alprostadil cream (Vitaros) was soon followed by an erection produced by the Vacuum. A sufficient rigidity for penetration was maintained by using an elastic ring at the base of the penis.

This arose in a very brief time span, in the absence of any physical discomfort due to the suction, and did not require any persistent mechanical manoeuvres to enhance rigidity, even starting with a completely flaccid penis.

The reproducibility of the use of Alprostadil cream in association with Vacuum was then confirmed at home, to the satisfaction of the patients (3).

\section{Discussion}

In severe ED, the simple use of a Vacuum device alone can lead to discomfort, not only physically, but also due to the continuous repeated mechanical manoeuvres needed to produce rigidity, when starting from a completely flaccid penis.

The preliminary insertion of Alprostadil cream in the urethra prepares the penis, to fit, quickly and safely, to the Vacuum, thanks to adequate tumescence being produced. 


\section{Conclusions}

When left to choose between the possible inadequacy of pharmacologic treatment and the prospect of a surgical prosthesis, treatment with Alprostadil cream in association with Vacuum (VITARUM) may constitute an acceptable bridging treatment, which is feasible with a favourable cost/benefit ratio, on the arduous pathway of treating severe erectile dysfunction, where palpable cavernous fibrosis is absent.

\section{REFERENCES}

1. Serefoglu EC, Saitz TR, Douglas LM, et al. The incidence and types of sexual dysfunction among prostate cancer patients. J Sex Med. 2012; 9 (suppl 5):303-335.

2. Osorio Cabello L, Martinez Salamanca FI, Egui Rojo A, et al. Penile morphometric changes after radical prostatectomy: impact of a rehabilitation program. J Sex Med. 2012; 9(suppl 5):320.

3. Ljunggren C, Stroberg P. A clinical sexologist appears to play an important role in a penile and sexual rehabilitation program may improve the outcome of sexual function one year after prostate cancer surgery. A prospective interventional study. J Sex Med. 2012; 9(suppl 5):319-320.

\section{Correspondence}

Franco Mantovani, MD

mantovanifranco@yahoo.it

Clinica San Giovanni

Via Civitali 71, Milano, Italy 